\title{
CALAgEM E APLicaÇÃo de COBALTO E MOLIBDÊNIO NA CULTURA DO AMENDOIM $\left({ }^{1}\right)$
}

\author{
EDUARDO FÁVERO CAIRES $\left({ }^{2}\right)$ e CIRO ANTONIO ROSOLEM $\left({ }^{3}\right)$
}

\begin{abstract}
RESUMO
O experimento compreendeu dois cultivos consecutivos de amendoim "das águas" em um latossolo vermelho-escuro distrófico, textura média, com o objetivo de avaliar os efeitos da calagem e da aplicação de cobalto e molibdênio nas sementes sobre a produção de amendoim. Empregaram-se quatro doses de calcário dolomítico calcinado: $0,4,6$ e 8 t/ha; dois cultivares de amendoim: Tatu e Tupã, e quatro tratamentos de sementes: não tratadas, tratadas com cobalto, com molibdênio e com cobalto mais molibdênio. Verificou-se que a calagem elevou a produção de amendoim em função do aumento proporcionado no número e massa de grãos por vagem. A máxima produção de vagens foi obtida para $\mathrm{pH}\left(\mathrm{CaCl}_{2} 0,01 \mathrm{M}\right) 5,0$, teor de cálcio trocável de $23,5 \mathrm{mmol}_{\mathrm{c}} / \mathrm{dm}^{3}$ e saturação por bases do solo de $50 \%$. A aplicação de cobalto, com ou sem molibdênio, nas sementes, não influenciou a produção de amendoim, independentemente das condiçōes de acidez do solo. A maior produtividade de vagens do cultivar Tupă, em relação ao 'Tatu', quando ocorre, é devida à maior proporção de cascas e não de grăos.
\end{abstract}

Termos de indexação: amendoim, calagem, cobalto, molibdênio.

\section{ABSTRACT \\ LIME, COBALT AND MOLYBDENUM EFFECTS IN PEANUT}

Two field experiments were conducted to study the effects of lime, cobalt and molybdenum on peanut yields. Seed treatments (cobalt, molybdenum, cobalt + molybdenum and no treatment) were applied in two peanut cultivars (Tatu and Tupã) grown in four rates of lime $(0,4,6$ and $8 \mathrm{t} / \mathrm{ha})$. Peanut yields were increased by liming owing to increase in the number of grains and grain yield per pod.

( ${ }^{1}$ Parte da Tese de Doutorado do primeiro autor. Recebido para publicação em 20 de dezembro de 1994 e aceito em 4 de agosto de 1995. (PR)

(2) Departamento de Ciência do Solo e Engenharia Agrícola - UEPG - Caixa Postal 992/3, 84010-330 Ponta Grossa

$\left({ }^{3}\right)$ Departamento de Agricultura e Melhoramento Vegetal, FCA - UNESP - Caixa Postal 237, 18603-970 Botucatu (SP). 
The highest pod yields were obtained in $\mathrm{pH}\left(\mathrm{CaCl}_{2} 0.01 \mathrm{M}\right) 5.0$, exchangeable calcium in the soil of $23.5 \mathrm{mmol}_{\mathrm{c}} / \mathrm{dm}^{3}$ and base saturation of $50 \%$. Cobalt and molybdenum had no effect on peanut yields. Although Tupã yielded more shelled peanuts, grain yields were similar in these cultivars.

Index terms: peanuts, liming, cobalt, molybdenum.

\section{INTRODUÇÃo}

Quando se trata de calagem na cultura do amendoim, existe na literatura um destaque muito grande para o cálcio, e a calagem é quase sempre considerada mais como uma operação fornecedora do nutriente do que corretiva da acidez. Essa situação prevalece porque as pesquisas foram quase sempre direcionadas para somente avaliar os efeitos do nutriente cálcio do calcário e não os da ação corretiva desse material na acidez do solo ou das conseqüências dessa acidez tanto desenvolvimento do amendoim como na sua produtividade (Nakagawa, 1983).

A importância do cálcio é ressaltada na literatura. Sua deficiência provoca vagens chochas e cascas frágeis, diminuindo o índice de fertilidade das flores, torna deficiente o crescimento de raízes e reduz o número de ginóforos formados (Colwell \& Brady, 1945; Walker et al., 1981).

De acordo com Blamey (1983), a calagem em solo ácido proporciona importante aumento na produção de amendoim, por reduzir o alumínio tóxico e melhorar a nodulação das plantas. Com o aumento do teor de alumínio trocável no solo, diminui o número de vagens, provável razão da baixa produção de amendoim em solos ácidos.

No entanto, Adams \& Pearson (1970) afirmaram que o amendoim não é muito influenciado pela acidez do solo e que a calagem não beneficia sua cultura pela precipitação de quantidades tóxicas de alumínio, mas, sim, por propiciar maiores teores de cálcio na região de desenvolvimento das vagens. Contudo, pH muito baixo pode conduzir à indisponibilidade de molibdênio, micronutriente necessário à simbiose bacteriana e, assim, afetar o fornecimento de nitrogênio às plantas.

O molibdênio talvez seja um dos micronutrientes com maior potencial de resposta para amendoim em solos tropicais (Quaggio et al., 1991), mas, mesmo ao nível internacional, são raros os trabalhos relacionando tal nutriente a essa cultura.

O cobalto também é capaz de afetar a absorção de nitrogênio por via simbiótica. Encontra-se bem estabelecido na literatura que o cobalto é essencial ao processo de fixação simbiótica de nitrogênio (Ahmed \& Evans, 1960) e ao crescimento do Rhizobium (Lowe \& Evans, 1962). Pesquisas sobre a aplicação de cobalto na cultura do amendoim também são escassas.

O presente trabalho teve por objetivo avaliar a influência da calagem e da aplicação de cobalto e molibdênio sobre a produção de dois cultivares de amendoim.

\section{MATERIAL E MÉTODOS}

O experimento foi instalado na Estação Experimental Lageado, da Faculdade de Ciências Agronômicas - UNESP, no município de Botucatu (SP), em um latossolo vermelho-escuro, textura média, cuja análise, realizada antes da instalação, revelou os seguintes resultados: $\mathrm{pH}\left(\mathrm{CaCl}_{2} 0,01 \mathrm{M}\right) 3,8 ; 80$ $\mathrm{mmol} / \mathrm{dm}^{3}$ de $\mathrm{H}^{+}+\mathrm{Al}^{3+} ; 4 \mathrm{mmol}_{\mathrm{c}} / \mathrm{dm}^{3} \mathrm{de} \mathrm{Ca}^{2+}$; $2 \mathrm{mmol} / \mathrm{dm}^{3}$ de $\mathrm{Mg}^{2+}, 1,0 \mathrm{mmol}_{\mathrm{d}} / \mathrm{dm}^{3} \mathrm{de} \mathrm{K}^{+} ; 5 \mathrm{mg} / \mathrm{dm}^{3}$ de P resina; $87 \mathrm{mmol} / \mathrm{dm}^{3}$ de CTC e $8 \%$ de saturação por bases.

Os tratamentos foram constituídos por quatro doses de calcário dolomítico calcinado com $95 \%$ de PRNT $(0,4,6$ e 8 t/ha), visando elevar a saturação por bases do solo a 50, 70 e $90 \%$; dois cultivares de amendoim (Tatu e Tupã) e quatro aplicações de nutrientes nas sementes: sementes não tratadas, tratadas com cobalto ( $34 \mathrm{~g} / \mathrm{ha}$ de $\mathrm{Co}$ ), com molibdênio (125 g/ha de Mo) e com cobalto mais molibdênio (34 g/ha de $\mathrm{Co}+125 \mathrm{~g} / \mathrm{ha}$ de $\mathrm{Mo}$ ). Aplicou-se o calcário apenas no primeiro cultivo, 
com 40 dias de antecedência da semeadura e incorporado por meio de grade niveladora, em terreno que sofrera aração, à profundidade de $0-20 \mathrm{~cm}$. O cobalto e o molibdênio foram empregados no tratamento de sementes, respectivamente, nas formas de sulfato de cobalto $\left(\mathrm{CoSO}_{4} .7 \mathrm{H}_{2} \mathrm{O}\right)$ e molibdato de amônio $\left[\left(\mathrm{NH}_{4}\right)_{6} \mathrm{Mo} \mathrm{O}_{24} .4 \mathrm{H}_{2} \mathrm{O}\right]$, sendo o delineamento experimental de blocos ao acaso em parcela subdividida, com três repetições.

As parcclas foram constituídas por seis linhas de amendoim, espaçadas de $0,5 \mathrm{~m}$, com o comprimento de $40 \mathrm{~m}$, as quais foram divididas em duas subparcelas de $20 \mathrm{~m}$ de comprimento e, estas, em quatro subsubparcelas de $5 \mathrm{~m}$ de comprimento. As parcelas receberam os níveis de calagem; as subparcelas, os cultivares de amendoim e, as subsubparcelas, os tratamentos de sementes. Entre as parcelas, manteve-se um espaço de $2 \mathrm{~m}$ sem aplicação de calcário para prevenir sua contaminação durante a incorporação e o preparo de solo. Foram consideradas como área útil as quatro linhas centrais de cada subsubparcela, desprezando-se $0,5 \mathrm{~m}$ de cada extremidade, compreendendo uma área de $8 \mathrm{~m}^{2}$.

A semeadura foi realizada manualmente, em 7 de novembro de 1990 e 11 de novembro de 1991 , em dois cultivos consecutivos "das águas", colocando-se 25 sementes por metro linear. Em cada semeadura, efetuou-se adubação básica no sulco com $100 \mathrm{~kg} / \mathrm{ha}$ de $\mathrm{P}_{2} \mathrm{O}_{5}$ e $40 \mathrm{~kg} / \mathrm{ha}$ de $\mathrm{K}_{2} \mathrm{O}$, respectivamente, nas formas de superfosfato simples e cloreto de potássio.

Amostras de solo foram tomadas em 21/11/90 e 24/1/92, retirando-se, por meio de trado de rosca, 12 subamostras das entrelinhas de cada parcela para compor uma amostra composta da camada de $0-20$ $\mathrm{cm}$. Nas amostras de terra coletadas, determina-

Quadro 1. Resultados de análises químicas de amostras de solo da camada arável, coletadas cerca de dois meses (1990/91) e dezesseis meses (1991/92) após a aplicação do calcário

\begin{tabular}{|c|c|c|c|c|c|c|}
\hline $\begin{array}{c}\text { Doses } \\
\text { de calcário }\end{array}$ & $\mathrm{pH}\left(\mathrm{CaCl}_{2}\right)$ & $\mathrm{H}^{+}+\mathrm{Al}^{3+}$ & $\mathrm{Ca}^{2+}$ & $\mathrm{Mg}^{2+}$ & $\mathrm{K}^{+}$ & V \\
\hline
\end{tabular}

t/ha $\mathrm{mmol} / \mathrm{dm}^{3}$

$1990 / 91$

$\begin{array}{lllllll}0 & 4,0 \mathrm{a}^{(1)} & 77,0 \mathrm{a} & 6,0 \mathrm{a} & 4,0 \mathrm{a} & 1,4 \mathrm{a} & 13 \mathrm{a} \\ 4 & 4,8 \mathrm{~b} & 37,7 \mathrm{~b} & 18,0 \mathrm{~b} & 16,0 \mathrm{~b} & 1,3 \mathrm{a} & 48 \mathrm{~b} \\ 6 & 5,2 \mathrm{~b} & 31,3 \mathrm{~b} & 24,0 \mathrm{~b} & 18,0 \mathrm{~b} & 1,3 \mathrm{a} & 58 \mathrm{c} \\ 8 & 5,7 \mathrm{c} & 24,0 \mathrm{c} & 36,0 \mathrm{c} & 28,0 \mathrm{c} & 1,1 \mathrm{a} & 73 \mathrm{~d}\end{array}$

$1991 / 92$

\begin{tabular}{cccccrc}
0 & $4,0 \mathrm{a}$ & $88,0 \mathrm{a}$ & $5,0 \mathrm{a}$ & $5,0 \mathrm{a}$ & $1,7 \mathrm{a}$ & $12 \mathrm{a}$ \\
4 & $4,6 \mathrm{~b}$ & $50,7 \mathrm{~b}$ & $13,0 \mathrm{ab}$ & $13,0 \mathrm{~b}$ & $1,8 \mathrm{a}$ & $35 \mathrm{~b}$ \\
6 & $5,1 \mathrm{c}$ & $37,7 \mathrm{bc}$ & $24,0 \mathrm{bc}$ & $20,0 \mathrm{c}$ & $2,2 \mathrm{a}$ & $55 \mathrm{c}$ \\
8 & $5,6 \mathrm{~d}$ & $26,7 \mathrm{c}$ & $35,0 \mathrm{c}$ & $21,0 \mathrm{c}$ & $1,7 \mathrm{a}$ & $68 \mathrm{c}$ \\
$\mathrm{CV}(\%) 1990 / 91$ & 2,96 & 5,59 & 15,18 & 10,74 & 29,38 & 6,10 \\
$\mathrm{CV}(\%) 1991 / 92$ & 3,09 & 16,94 & 24,96 & 12,93 & 19,51 & 11,7 \\
\hline
\end{tabular}

(1) Letras iguais nas colunas, dentro de cada ano de cultivo, não diferem significativamente pelo teste de Tukey a $5 \%$. 


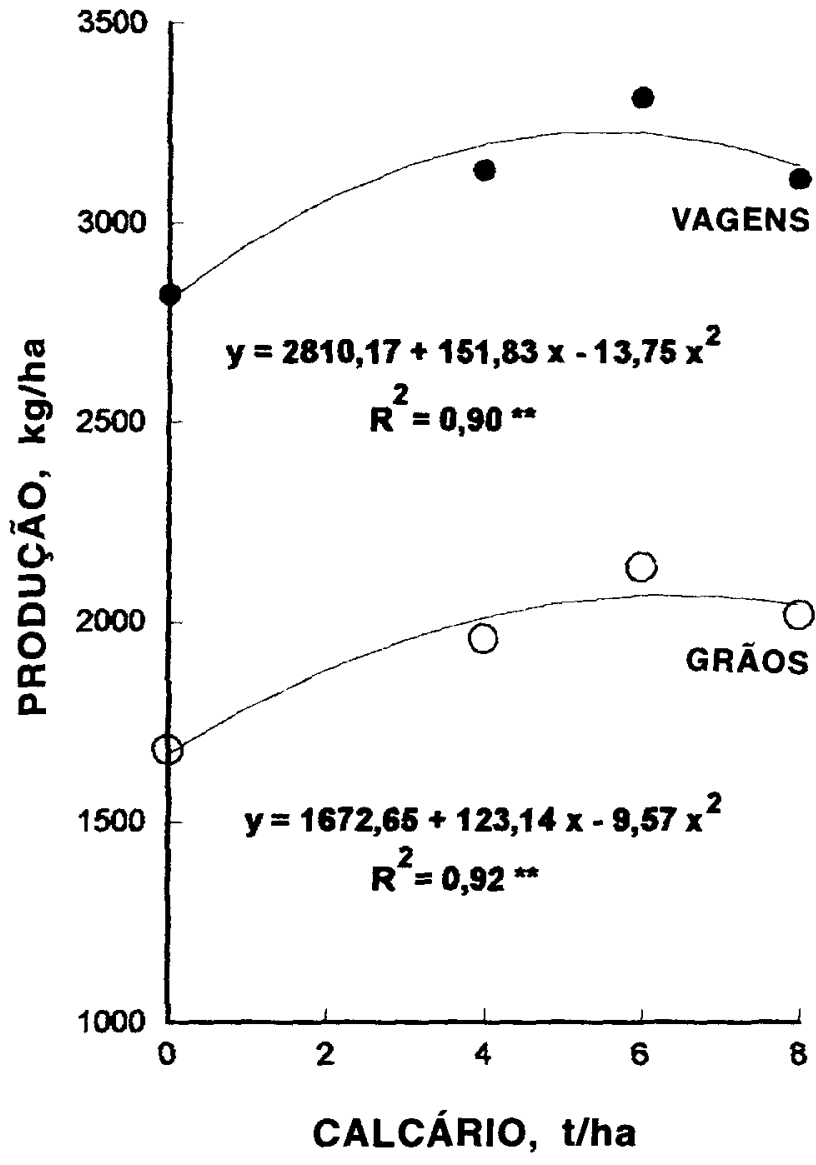

Figura 1. Resultados da calagem sobre a produção de vagens e grãos de amendoim, no segundo cultivo "das águas", $1991 / 92$.

Zuadro 2. Resultados da calagem na produção de vagens e grãos de amendoim, no primeiro cultivo "das águas", 1990/91

\begin{tabular}{llc}
\hline \multirow{2}{*}{ Jalcário } & \multicolumn{2}{c}{ Produção } \\
\cline { 2 - 3 } & Vagens & Grãos \\
\hline & $\mathrm{t} / \mathrm{ha}$ & $\mathrm{kg} / \mathrm{ha}$ \\
4 & $2214 \mathrm{~A}\left({ }^{1}\right)$ & $1472 \mathrm{~A}$ \\
6 & $2265 \mathrm{~A}$ & $1527 \mathrm{~A}$ \\
8 & $2714 \mathrm{~A}$ & $1875 \mathrm{~A}$ \\
\hline
\end{tabular}

) Letras iguais nas colunas não diferem significativamente pelo ste de Tukey a $5 \%$. ram-se o $\mathrm{pH}$, os cátions trocáveis e o $\mathrm{H}^{+}+\mathrm{Al}^{3+}$, segundo Raij \& Quaggio (1983).

A avaliação da produtividade de vagens foi realizada aos 110 e 100 dias após a emergência, no $1 .^{\circ}$ e $2 .^{\circ}$ ano de cultivo respectivamente, colhendo-se manualmente as plantas. Avaliou-se a produtividade de grãos, trilhando-se a produção de vagens em máquina debulhadora manual. No segundo cultivo de amendoim (1991/92), avaliaram-se, também, os componentes de produção. Para tanto, retiraram-se dez plantas por subsubparcela, cem dias após a emergência, realizando-se as seguintes determinações: número e massa de vagens por planta e número e massa dc grãos por vagem.

A análise da variância seguiu o modelo em parcelas subsubdivididas, tendo-se comparado as médias pelo teste de Tukey a 5\% de probabilidade. No caso de interaçóes significativas, realizou-se desdobramento.

Mediante análises de regressão por polinômios ortogonais, ajustaram-se equações de regressão aos dados de produção de vagens e grãos em função da calagem, pH, saturação por bases e teor de cálcio trocável do solo, e de número e massa de grãos por vagem e massa de vagens por planta em função da calagem. Consideraram-se apenas as rcgressões de coeficientes de determinação significativos ao nível de $5 \%$.

Quadro 3. Número de vagens por planta de cultivares de amendoim, em função da calagem, no segundo cultivo "das águas", 1991/92

\begin{tabular}{cc}
\hline Calcário & Vagens/Planta \\
\hline t/ha & $\mathrm{n}^{\circ}$ \\
0 & $9,92 \mathrm{~A}\left({ }^{1}\right)$ \\
4 & $8,74 \mathrm{~A}$ \\
6 & $9,97 \mathrm{~A}$ \\
8 & $9,82 \mathrm{~A}$ \\
\hline
\end{tabular}

(1) Letras iguais nas colunas não diferem significativamente pelo teste de Tukey a $5 \%$. 


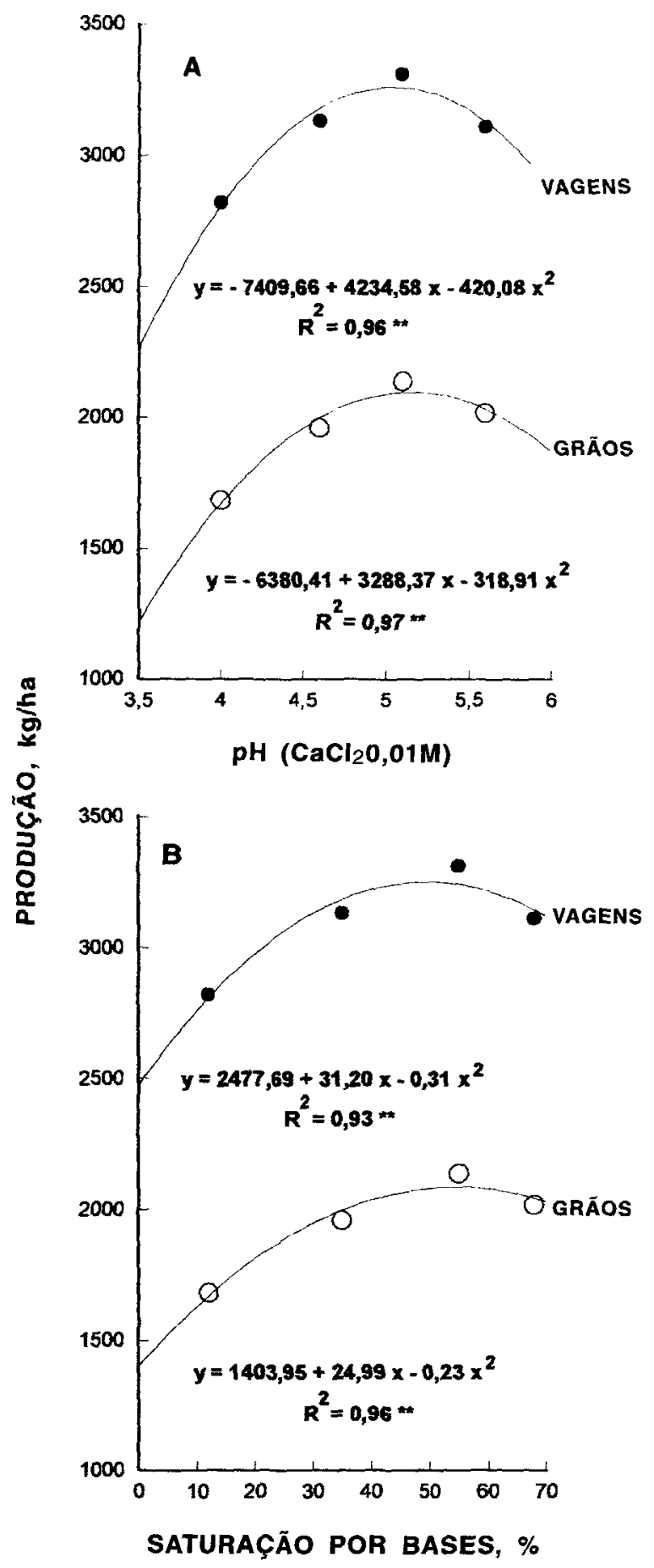

Figura 2. Relações entre a produção de vagens e grāos de amendoim e o pH em $\mathrm{CaCl}_{2} \quad 0,01 \mathrm{M}$ (A) e a saturação por bases do solo (B), no segundo cultivo "das águas", 1991/92.

\section{RESULTADOS E DISCUSSĀO}

Os resultados de análises químicas do solo na camada arável em dois períodos constam do quadro 1. Nota-se que, já aos 55 dias após a aplicação do calcário, ocasião da emergência das plântulas do primeiro cultivo (1990/91), o corretivo havia apresentado reação satisfatória no solo. Esperava-se tal efeito em função do corretivo utilizado, do tempo decorrido da aplicação (Alcarde et al., 1989) e da precipitação pluvial durante esse período. É evidente o efeito da calagem no aumento dos valores de $\mathrm{pH}$ e saturação por bases, bem como nos teores de cálcio e magnésio.

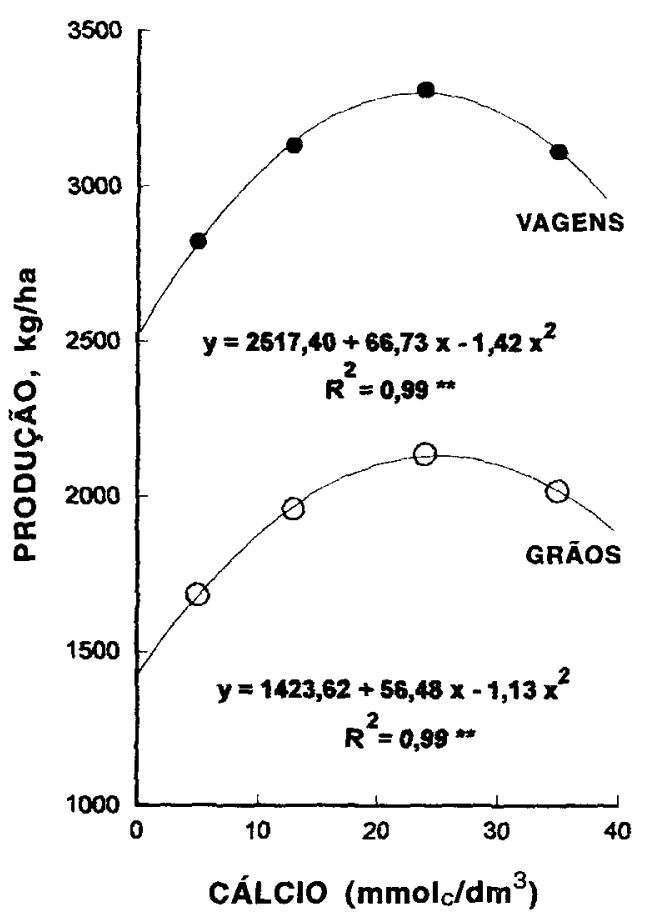

Figura 3. Relações entre a produção de vagens e grãos de amendoim e os teores de cálcio trocável no solo, no segundo cultivo "das águas", 1991/92. 
A calagem, porém, praticamente não interferiu nos teores de potássio. Esse efeito da calagem perdurou, pelo menos, até os 16 meses após a aplicação do calcário, fase de enchimento dos grãos do segundo cultivo (1991/92).

De acordo com a análise da variância efetuada para os parâmetros estudados, somente houve interação significativa ao nível de $5 \%$ para massa de grãos por vagem, entre cultivar e tratamento de sementes, tendo sido realizado o desdobramento. Para os demais parâmetros avaliados, não se observaram interações significativas, sendo os efeitos dos tratamentos discutidos separadamente.

Os efeitos da calagem sobre a produção de vagens e grãos de amendoim no primeiro cultivo encontram-se no quadro 2. Não foi possível ajustar nenhuma equação de regressão a esses dados de produção do primeiro ano. O teste de Tukey a 5\% de probabilidade não revelou diferenças significativas, embora tenha havido tendência de resposta do amendoim à aplicação do calcário até a dose de $6 \mathrm{t} / \mathrm{ha}$. Salienta-se, no entanto, que nesse ano de cultivo foram detectados problemas com pragas de solo e a colheita foi realizada em época muito chuvosa, o que resultou em coeficientes de variação muito altos $(56,89 \%$ para produção de vagens e $60,68 \%$ para produção de grãos), devido às perdas ocorridas, dificultando a interpretação dos resultados.

No segundo cultivo, a produção de vagens e grãos de amendoim foi influenciada significativamente pela calagem, com resposta quadrática, conforme se pode observar na figura 1.

Nota-se que, de acordo com a curva calculada, a máxima produção de vagens foi obtida para a dose de 5,5 t/ha de calcário. Respostas positivas do amendoim à aplicação de calcário também foram obtidas por Tella et al. (1971); Quaggio et al. (1982) e Caires \& Rosolem (1993).

Na figura 2, apresentam-se as relações obtidas entre a produção de vagens e grãos, do segundo cultivo, e dois parâmetros da fertilidade do solo: $\mathrm{pH}\left(\mathrm{CaCl}_{2} \quad 0,01 \mathrm{M}\right)$ e saturação por bases. Como se pode notar, houve aumento na produção de vagens e grãos relacionado ao acréscimo do valor
pH e da saturação por bases do solo, proporcionado pela calagem.

A produção máxima de vagens, de acordo com a curva ajustada, foi alcançada para $\mathrm{pH}\left(\mathrm{CaCl}_{2}\right.$ $0,01 \mathrm{M}) 5,0$ e saturação por bases de $50 \%$. Esses valores são superiores aos observados por Quaggio et al. (1982) para o cultivar Tatu, e estão muito próximos dos obtidos por Caires \& Rosolem (1993) para o 'Oirã'.

A produção de vagens e grãos, do segundo cultivo, também foi afetada pelo teor de cálcio trocável no solo, como mostra a figura 3 . Nota-se que, na curva calculada, a máxima produção de vagens ocorreu para teor de cálcio trocável de $23,5 \mathrm{mmol}_{\mathrm{c}} / \mathrm{dm}^{3}$. As exigências em cálcio determinadas neste trabalho muito se assemelham às observadas por Caires \& Rosolem (1993), para o cultivar Oirã, e por Bell (1985) para amendoim do grupo Virgínia.

O aumento de produção de amendoim pela calagem foi ocasionado pelo aumento do número e massa de grãos por vagem - Figura 4.

O número de vagens por planta não se mostrou influenciado pela correção da acidez do solo, devido à aplicação de calcário (Quadro 3). Tal parâmetro, portanto, não deve ter interferido nos aumentos de produção de amendoim.

O aumento do número e massa de grãos por vagem, proporcionado pela calagem (Figura 4), por sua vez, resultou em maior massa de vagens por planta (Figura 5).

É necessário destacar a importância do fornecimento de cálcio pela calagem para conseguir esses efeitos, pois, de acordo com York \& Colwell (1951), uma das funções primárias do cálcio na nutrição do amendoim é auxiliar no maior desenvolvimento dos grãos, sendo os resultados positivos mais evidentes em solos com baixo teor do nutriente.

No entanto, solos com baixo teor de cálcio possuem, normalmente, baixo valor de $\mathrm{pH}$, tornando-se difícil isolar os efeitos da calagem.

A aplicação de cobalto e molibdênio nas sementes não influenciou a produção de vagens e grãos de amendoim, nos dois cultivos, conforme mostra 
a figura 6. Contudo, Hafner et al. (1992) conseguiram, com a aplicação de molibdênio, e Raj (1987), com a de cobalto, nas sementes, aumentar a produção de amendoim.

O número e a massa de vagens por planta e o número de grãos por vagem - Figura 7 - também não foram influenciados significativamente pelo tratamento de sementes com cobalto e molibdênio.

Embora tenha havido interação significativa entre cultivar e tratamento de sementes, para massa de grãos por vagem, pode-se notar, no quadro 4 , que a massa de grãos por vagem dos cultivares não foi afetada pela aplicação de cobalto e molibdênio nas sementes. Apenas os cultivares tiveram comportamento diferenciado de acordo com o tratamento de sementes com cobalto e molibdênio.
No quadro 5, apresentam-se os resultados de produção de vagens e grãos dos cultivares de amendoim, nos dois cultivos, e de número e massa de vagens por planta e número de grãos por vagem no segundo cultivo. $O$ 'Tupã' apresentou maior produção de vagens do que o 'Tatu' no segundo ano de cultivo. Não se observaram, porém, diferenças significativas entre os cultivares com relação à produção de grãos. Isso mostra que a maior produção de vagens do 'Tupã', quando ocorre, se deve à maior produção de cascas e não de grãos. Esses resultados confirmam os de Caires \& Rosolem (1993).

O 'Tupã' apresentou maior número e massa de vagens por planta em relação ao 'Tatu'. Certamente, foi isso que conferiu àquele maior produção de vagens, no segundo cultivo, 1991/92.

Quadro 4. Produção de grãos por vagem de cultivares de amendoim em função da aplicação de cobalto e molibdênio, no segundo cultivo "das águas", 1991/92

\begin{tabular}{|c|c|c|c|c|c|}
\hline \multirow{2}{*}{ Cultivar } & \multicolumn{4}{|c|}{ Tratamento de Sementes } & \multirow{2}{*}{ Média } \\
\hline & $\mathrm{T}$ & $\mathrm{Co}$ & Mo & $\mathrm{Co}+\mathrm{Mo}$ & \\
\hline Tatu & $0,82 \mathrm{Aa}\left({ }^{1}\right)$ & $0,91 \mathrm{Ba}$ & $0,87 \mathrm{Ba}$ & $0,86 \mathrm{Ba}$ & 0,86 \\
\hline Tupã & $0,79 \mathrm{Aa}$ & $0,71 \mathrm{Aa}$ & $0,71 \mathrm{Aa}$ & $0,72 \mathrm{Aa}$ & 0,73 \\
\hline Média & 0,80 & 0,81 & 0,79 & 0,79 & -- \\
\hline
\end{tabular}

(') Letras minúsculas iguais nas linhas ou maiúsculas nas colunas não diferem significativamente pelo teste de Tukey a $5 \%$.

Quadro 5. Produção de vagens e grãos de cultivares de amendoim, em dois cultivos consecutivos, e número e massa de vagens por planta e número de grãos por vagem dos cultivares no segundo cultivo "das águas", 1991/92

\begin{tabular}{|c|c|c|c|c|c|c|c|}
\hline \multirow{3}{*}{ Cultivar } & \multicolumn{4}{|c|}{ Produçāo } & \multirow{3}{*}{\multicolumn{2}{|c|}{$\frac{\text { Vagem/planta }}{1991 / 92}$}} & \multirow{3}{*}{$\frac{\text { Grãos/vagem }}{1991 / 92}$} \\
\hline & Vagens & \multirow{2}{*}{$\frac{\text { Grãos }}{1}$} & Vagens & \multirow{2}{*}{$\frac{\text { Grãos }}{2}$} & & & \\
\hline & $1990 / 91$ & & $1991 / 92$ & & & & \\
\hline Tatu & $2353 A^{(1)}$ & $1662 \mathrm{~A}$ & $2948 A$ & $1942 \mathrm{~A}$ & $7,83 \mathrm{~A}$ & $9,59 \mathrm{~A}$ & $2,14 \mathrm{~B}$ \\
\hline Tupã & $2383 \mathrm{~A}$ & $1545 \mathrm{~A}$ & $3241 B$ & $1957 \mathrm{~A}$ & $11,40 \mathrm{~B}$ & $12,11 B$ & $1,43 \mathrm{~A}$ \\
\hline
\end{tabular}

(1) Letras iguais nas colunas não diferem significativamente pelo teste de Tukey a $5 \%$. 

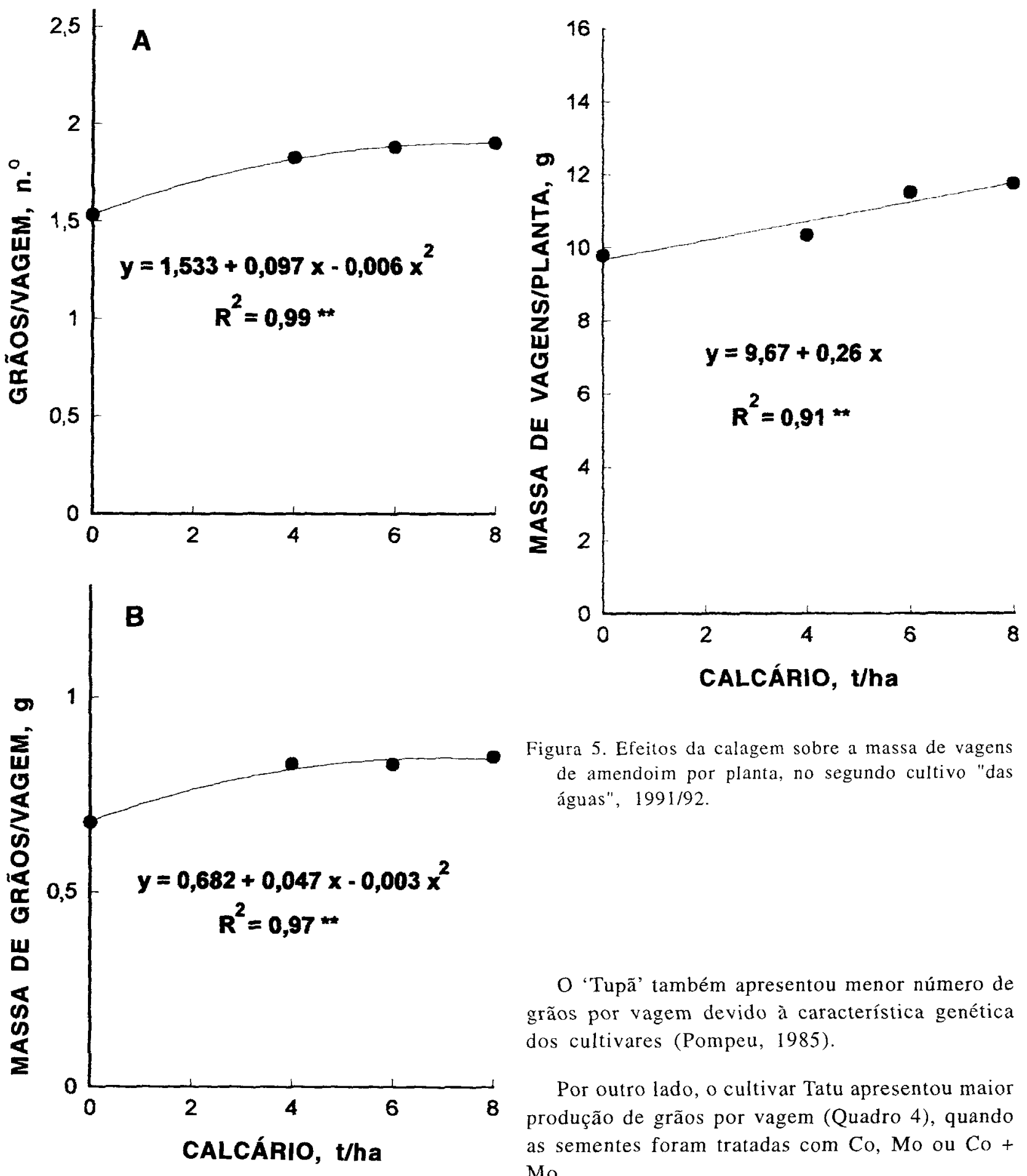

Figura 5. Efeitos da calagem sobre a massa de vagens de amendoim por planta, no segundo cultivo "das águas", $1991 / 92$.

O 'Tupä' também apresentou menor número de grãos por vagem devido à característica genética dos cultivares (Pompeu, 1985).

Por outro lado, o cultivar Tatu apresentou maior produção de grãos por vagem (Quadro 4), quando as sementes foram tratadas com $\mathrm{Co}, \mathrm{Mo}$ ou $\mathrm{Co}+$ Mo.

Figura 4. Efeitos da calagem sobre o número (A) e a massa (B) de grãos de amendoim por vagem, no segundo cultivo "das águas", 1991/92.

É interessante ressaltar que essas diferenças não proporcionaram variações significativas na produção de grãos dos cultivares. 


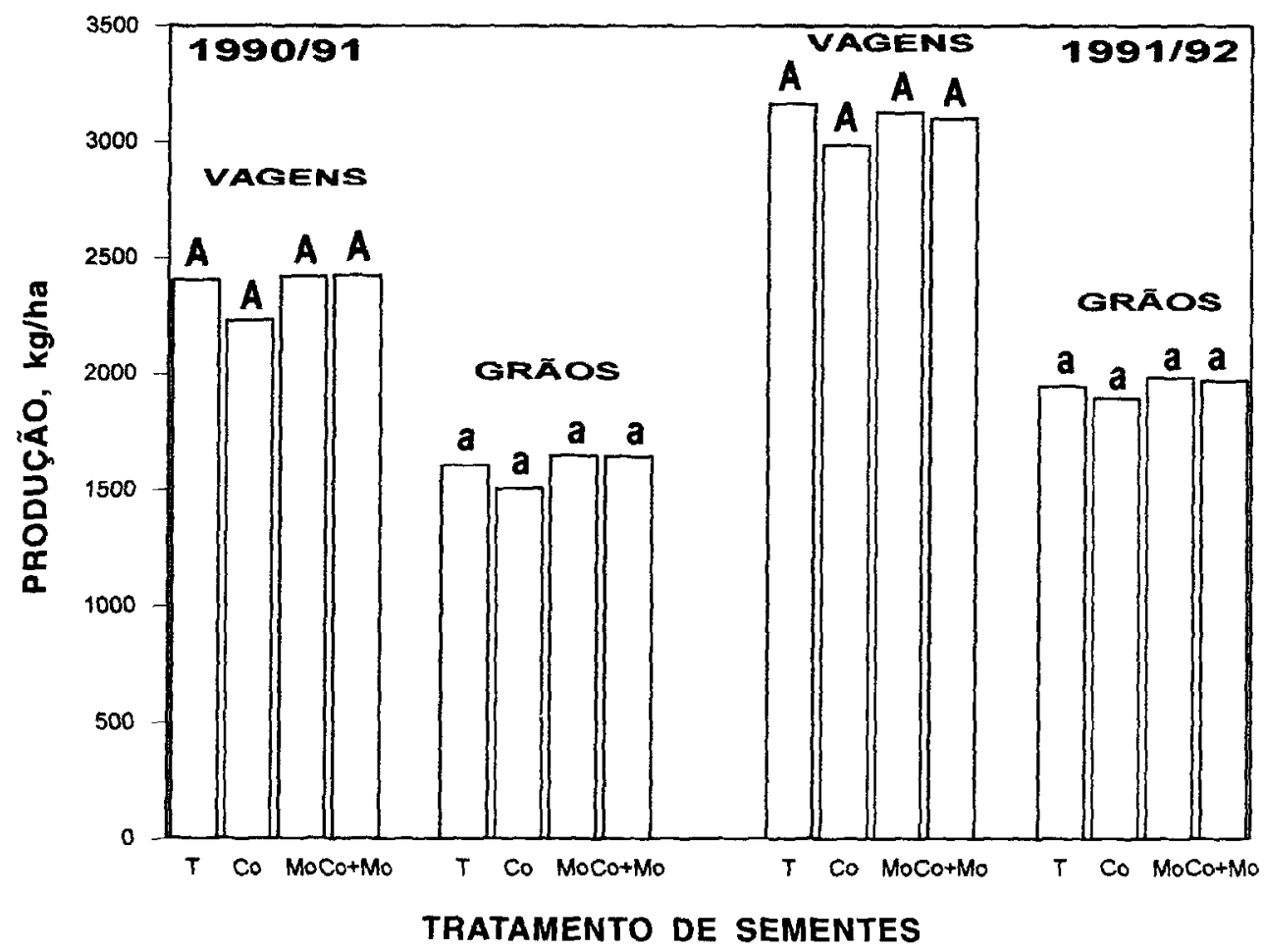

Figura 6. Resultados da aplicação de cobalto e molibdênio na produção de vagens e grãos de amendoim, $\mathrm{cm}$ dois cultivos consecutivos. Letras iguais não diferem significativamente pelo teste de Tukey a $5 \%$.

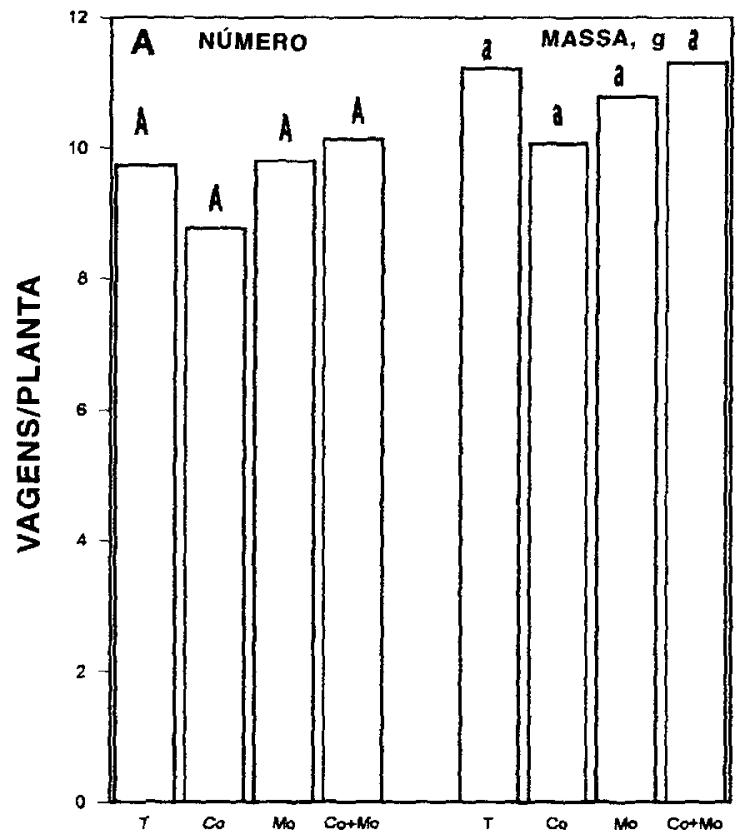

TRATAMENTO DE SEMENTES

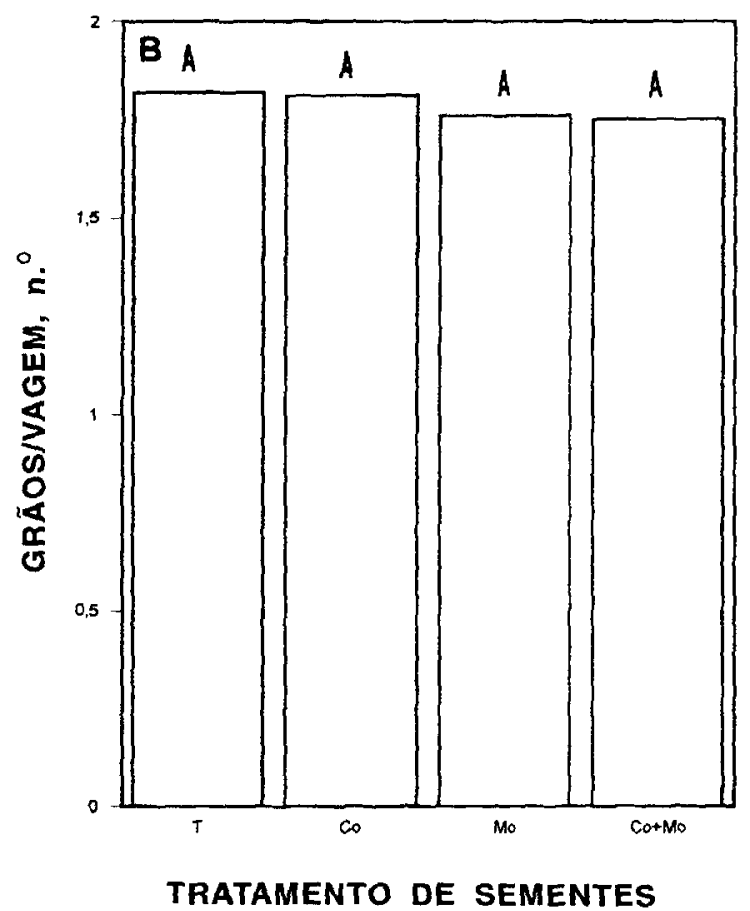

igura 7. Efeitos da aplicação de cobalto e molibdênio sobre o número e a massa de vagens de amendoim por planta (A) e o número de grãos de amendoim por vagem (B), no segundo cultivo "das águas", 1991/92. Letras iguais não diferem significativamente pelo teste de Tukey a $5 \%$. 


\section{CONCLUSÖES}

1. A calagem aumentou a produção de amendoim por proporcionar aumento no número de grãos por vagem.

2. A máxima produção de vagens foi obtida para valor $\mathrm{pH}\left(\mathrm{CaCl}_{2} 0,01 \mathrm{M}\right) 5,0$; teor de cálcio trocável de $23,5 \mathrm{mmol}_{\mathrm{c}} / \mathrm{dm}^{3}$ e saturação por bases do solo de $50 \%$.

3. A aplicação de cobalto e/ou molibdênio nas sementes não influenciou a produção de amendoim, independentemente das condições de acidez do solo.

4. A maior produtividade de vagens do cultivar Tupã, em relação ao 'Tatu', quando ocorre, se deve à maior proporção de cascas e não de grãos.

\section{REFERÊNCIAS BIBLIOGRÁFICAS}

ADAMS, F. \& PEARSON, R.W. Differential response of cotton and peanuts to subsoil acidity. Agronomy Journal, Madison, 62:9-12, 1970.

AHMED, S. \& EVANS, H.J. Cobalt: a micronutrient element for growth of soybean under symbiotic conditions. Soil Science, Baltimore, 90:205-210, 1960.

ALCARDE, J.C.; PAULINO, V.T. \& DENARDIN, J.S. Avaliação da reatividade de corretivos de acidez do solo. Revista Brasileira de Ciência do Solo, Campinas, 13:387-392, 1989.

BELL, M.J. Calcium nutrition of peanuts (Arachis hypogaea L.) on Cockatoo Sands of the Ord River Irrigation Area. Australian Journal of Experimental Agriculture, Melbourne, 25:642-648, 1985.

BLAMEY, F.P.C. Acid soil infertility effects on peanut yields and yield components. Communication in Soil Science and Plant Analysis, New York, 14:373-386, 1983.

CAIRES, E.F. \& ROSOLEM, C.A. Calagem em genótipos de amendoim. Revista Brasileira de Ciência do Solo, Campinas, 17:193-202, 1993.

COLWELL, W.E. \& BRADY, N.C. The effect of calcium on certain characteristics of peanut fruit. Journal of the American Society of Agronomy, Madison, 37:696-708, 1945.
HAFNER, H.; NDUNGURU, B.J.; BATIONO, A. \& MARSCHNER, H. Effect of nitrogen, phosphorus and molybdenun application on growth and symbiotic N2-fixation of groundnut in an acid sandy soil in Niger. Fertilizer Research, Dordrecht, 31:69-77, 1992.

LOWE, R.H. \& EVANS, H.J. Cobalt requeriment for the growth of Rhizobia. Journal of Bacteriology, Washington, 83:210, 1962.

NAKAGAWA, J. Acidez e calagem no amendoim. In: REUNIĀO BRASILEIRA DE FERTILIDADE DO SOLO, 15., Campinas, 1983. Anais. Campinas, SBCS, 1983. p.179-185.

POMPEU, A.S. Novos cultivares do IAC-Amendoim. O Agronômico, Campinas, 37:87-88, 1985.

QUAGGIO, J.A.; DECHEN, A.R. \& RAIJ, B. van. Efeitos da aplicação de calcário e gesso sobre a produção de amendoim e lixiviação de bases no solo. Revista Brasileira de Ciência do Solo, Campinas, 6 :186-194, 1982.

QUAGGIO, J.A.; SILVA, N.M. \& BERTON, R.S. Culturas oleaginosas. In: FERREIRA, M.E. \& CRUZ, M.C.P. Micronutrientes na agricultura. Piracicaba, Potafos/CNPq, 1991 . p.445-484.

RAIJ, B.van \& QUAGGIO, J.A. Métodos de análise do solo para fins de fertilidade. Campinas, Instituto Agronômico, 1983. 3lp. (Boletim técnico, 81)

RAJ, A.S. Cobalt nutrition of pigeonpea and peanut in relation to growth and yield. Journal of Plant $\mathrm{Nu}$ trition, New York, 10:2137-2145, 1987.

TELLA, R.; CANECCHIO FILHO, V.; ROCHA, J.L.V. \& FREIRE, E.S. Efeito da adubação do amendoim com nitrogênio, fósforo e potássio, na presença e ausência de calcário. Bragantia, Campinas, 30:39-47, 1971.

WALKER, M.E.; MULLINIX JR., B.G. \& KEISLING, T.C. Calcium level in the peanut fruiting zone as influenced by gypsum particle size and application rate and time. Communications in Soil Science and Plant Analysis, New York, 12:427-439, 1981.

YORK JR., E.T. \& COLWELL, W.E. Soil properties, fertilization and maintenance of soil fertility. In: SYMPOSIUM THE PEANUT, THE UNPREDICTABLE LEGUME. Washington, 1951. Proceedings. Washington, National Fertilizers Association, 1951. p.122-171. 